Spring 4-24-2020

\title{
Occupational Therapy's Role in Adapting Residential Youth Camps for Increased Inclusion
}

\author{
Brittany Tate \\ University of St. Augustine for Health Sciences \\ DOI: https://doi.org/10.46409/sr.WJDW2405
}

Follow this and additional works at: https://soar.usa.edu/capstones

Part of the Disability and Equity in Education Commons, Disability Studies Commons, and the Outdoor Education Commons

\section{Recommended Citation}

Tate, B. (2020). Occupational Therapy's Role in Adapting Residential Youth Camps for Increased Inclusion. [Doctoral project, University of St Augustine for Health Sciences]. SOAR @ USA: Student Capstone Projects Collection. https://doi.org/10.46409/sr.WJDW2405

This Capstone is brought to you for free and open access by the Student Research at SOAR @ USA. It has been accepted for inclusion in Student Capstone Projects by an authorized administrator of SOAR @ USA. For more information, please contact soar@usa.edu, erobinson@usa.edu. 
OCCUPATIONAL THERAPY'S ROLE IN ADAPTING RESIDENTAL YOUTH CAMPS FOR INCREASED INCLUSION

by

Brittany E. Tate

A Capstone Presented in Partial Fulfillment of the Requirement for the Degree of DOCTOR OF OCCUPATIONAL THERAPY

University of St. Augustine for Health Sciences

April, 2020 


\title{
OCCUPATIONAL THERAPY'S ROLE IN ADAPTING RESIDENTAL YOUTH CAMPS FOR INCREASED INCLUSION
}

\author{
by \\ Brittany E. Tate \\ has been approved
}

April, 2020

APPROVED:

Susan MacDermott, OTD, OTR/L, Doctoral Coordinator

Becki Cohill, OTD, OTR/L, Doctoral Coordinator

Erin Schwier, EdD, OTD, OTR/L, Program Director

ACCEPTED AND SIGNED:

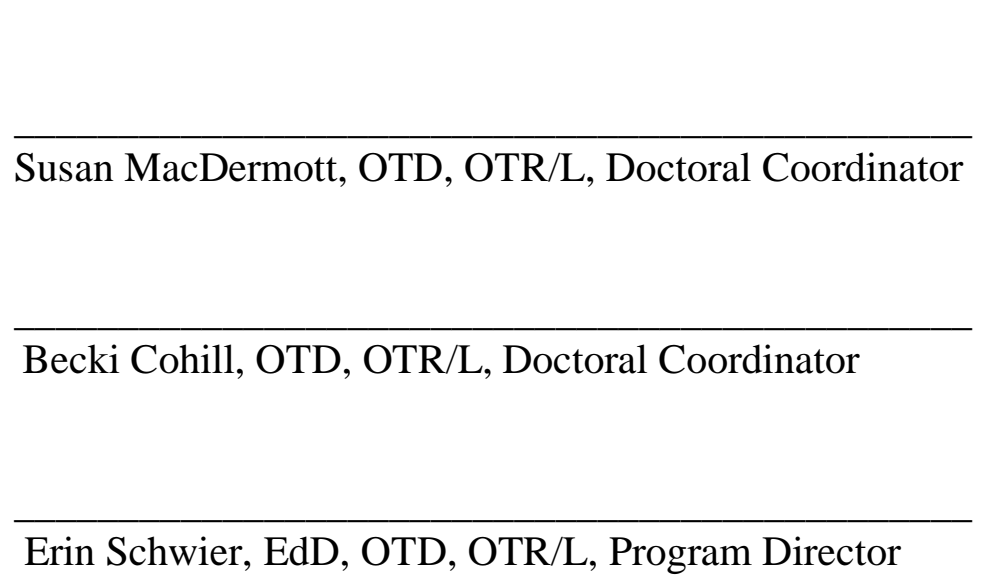


Table of Contents

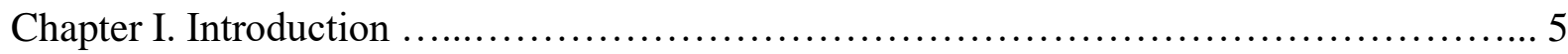

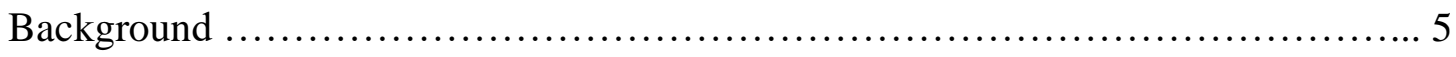

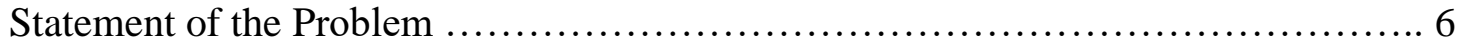

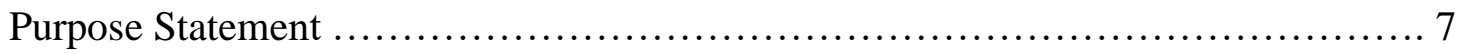

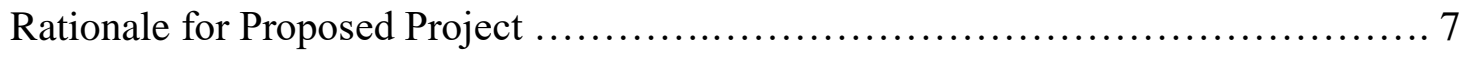

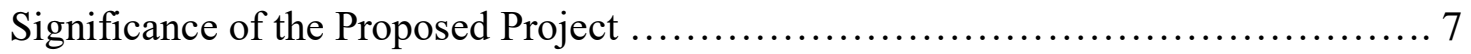

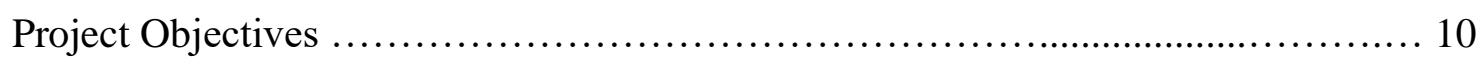

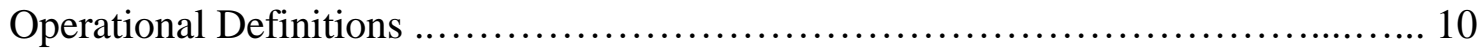

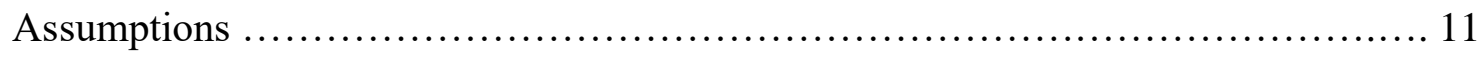

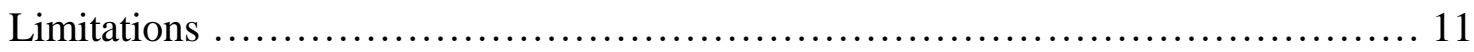

Delimitations ........................................................................ 11

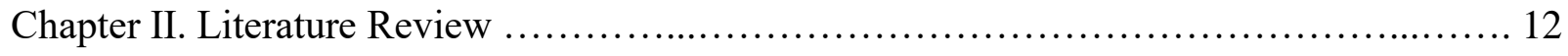

Positive Impact on Youth Development ....................................... 12

Positive Impact of Camp on Youth with Disabilities ............................... 13

The Emerging Role of Therapy in Adaptive Summer Camps ......................... 14

Literature Review Summary …………………………................................... 15

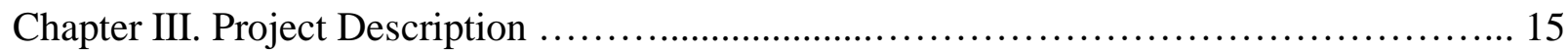

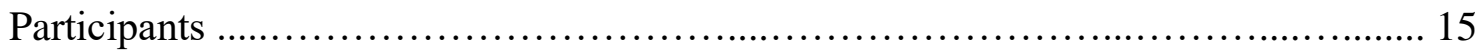

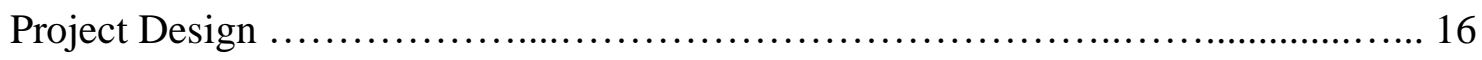

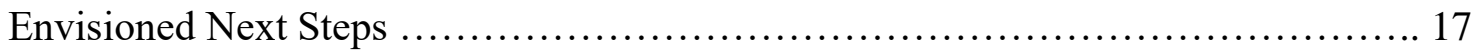

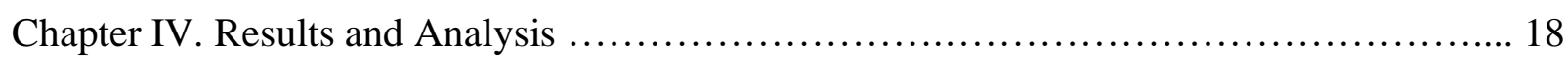

Results and Analysis ........................................................ 18 
Theme 1: Increase Training on Inclusion Methods ............................... 19

Theme 2: Challenging and Diverse Terrain ................................. 20

Theme 3: Increase Discussion on Inclusion ............................... 21

Theme 4: Increase Knowledge of Students' Needs ............................ 21

Findings from Semi-Structured Interviews with Staff and Parents ......................... 23

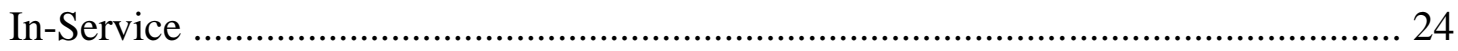

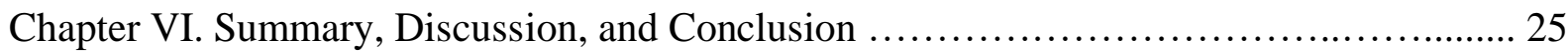

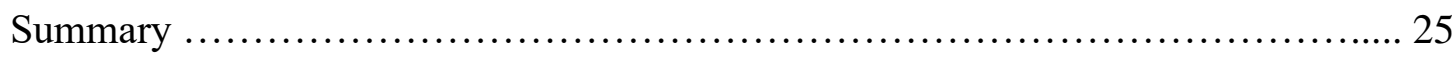

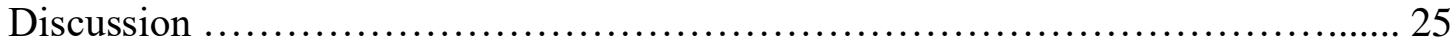

Current Pathfinder Ranch Inclusion Strengths Observed .................................... 26

Recommendations for Pathfinder Ranch ............................................................ 26

Lack of Staff with Experience Working with Special Needs ................................ 27

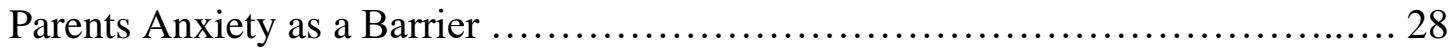

Environmental Limitations .................................................. 29

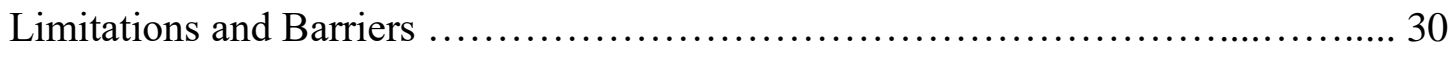

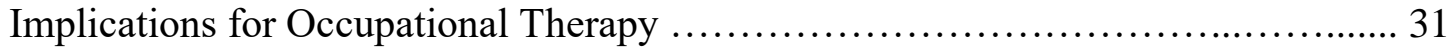

Future Research Studies ............................................... 32

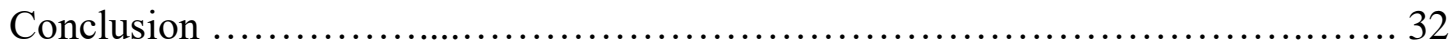

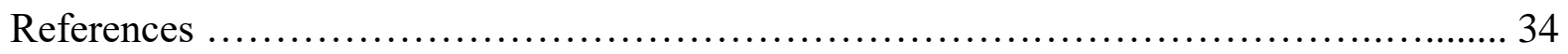

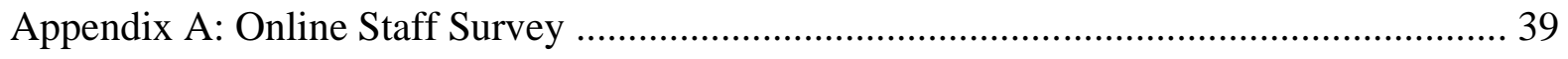

Appendix B: Camp Inclusion Trivia Game .................................................................. 43

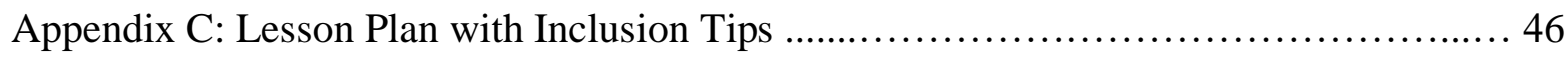

Appendix D: Recommendations for Pathfinder Ranch ….......................................... 55 
Occupational Therapy's Role in Adapting Residential Youth Camps for Increased Inclusion

\section{Background}

Each year, summer camps serve more than 11 million youth in the United States (US) (Wilson, Sibthorp, \& Brusseau, 2017). Such programs are crucial to support children while they are out of school due to lack of structure during the summer months. Summer camps provide children with new experiences and give them opportunities to build confidence, social skills, and peer relationships (Wilson et al., 2017). The semi-structured outdoor camp activities are designed to promote creative thinking, teamwork, problem-solving, and build group trust (Hellman \& Gwinn, 2017).

Summer camp can enrich the lives of youth by providing positive experiences that have long-term effects (Snider \& Farmer, 2017). Feenstra (2015) articulates that exposing campers to new interests and challenging experiences within the context of supportive relationships promotes positive youth development and growth. Snider and Farmer (2017) also indicate that residential summer camp changes lives through positive relationships. In addition, they identify further program benefits, such as improved independence and life skills and increased outdoor affinity, gains which are carried by individuals from childhood into adulthood (Snider \& Farmer, 2017).

Occupational therapists employ activity adaptation, environmental analysis, and meaningful occupation through play (Hanscom \& Schoen, 2014). These domains can be used to create nature programs like residential youth camps. Harper (2017) notes both types of programs embrace the values of adventure and challenge, balanced by safety and support, to promote optimal youth development. 
Occupational therapy (OT) is an emerging area of practice throughout summer camps in the US (Hanscom \& Schoen, 2014). Hanscom and Schoen (2014) recommended strategically combining OT with traditional camp programming to create an emotionally, physically, and spiritually safe environment that promotes optimal attending and task follow through. Individualized intervention strategies can be infused into the day to support each camper's successful participation. For example, Purvis, Cross, Federici, Johnson, and McKenzie (2007) describe sensory diets, which incorporate vestibular, proprioceptive, and tactile inputs to facilitate improved self-regulation.

\section{Statement of the Problem}

Summer camp has been shown to enhance positive youth development, as it meets motivational needs and promotes intrinsic engagement (Halsall, Kendellen, Bean, \& Forneris, 2016). However, not all youth have an equal opportunity to partake in the experience (Shefter, Uhrman, Tobin, \& Kress, 2017). McCarthy (2015) states that two percent of American Camp Association camps exclusively serve youth with special medical needs. Further, only seven percent are inclusive (Hall, Dunlap, Causton-Theoharis, \& Theohari, 2019). The American Camp Association is the largest accrediting organization of summer camps in the US (McCarthy, 2015).

Illness-specific summer camps are often hosted at facilities with ADA accommodations, such as a residential school campus designed for special needs children (Woods \& Cronin, 2018). Youth who experience chronic conditions, illness, or impairments are at risk of experiencing social isolation, emotional, and social challenges (McCarthy, 2015). Therefore, summer camp has become an increasingly popular therapeutic intervention for this population (McCarthy, 2015). This increase in popularity represents a window of opportunity for OT to 
consult with summer camps to create a welcoming environment for all. However, there is limited research on inclusive camps, which makes evidence-based practice problematic.

\section{Purpose Statement}

The purpose of this capstone project is to explore the populations served within a residential youth camp, identify barriers to participation, and recommend adaptations to the environment to promote a more inclusive environment. Enhancing positive youth development has been a fundamental theme that has emerged through the literature and with basis for this capstone project (Halsall et al., 2016).

\section{Rationale for Proposed Project}

Summer camp can be an effective intervention and therapeutic tool for youth coping with physical or emotional challenges because it provides enjoyable experiences, facilitates opportunities to achieve personal goals, creates supportive peer bonds, and encourages positive development (McCarthy, 2015). However, parents are often hesitant to allow their children to attend summer camp due to fears that staff may not be equipped to handle complications or that adaptations will not be available to meet their children's needs (Moola, Faulkner, White, \& Kirsh, 2014). McCarthy (2015) adds that parents' anxiety and desire to continually monitor their children can limit participation in crucial developmental opportunities, such as summer camp. Occupational therapy can address parents' concerns by educating and consulting on adaptations and modifications to promote an all-encompassing environment.

\section{Significance of the Proposed Project}

Creating a more inclusive context is essential to ensure quality of life (QOL). This can be accomplished in the area of positive youth development by including all abilities at camp. For example, in a study by Walker, Barry, and Bader (2010), an OT student implemented an assistive 
technology adaptation to improve communication by utilizing visual supports for children with autism spectrum disorder (ASD) at a summer camp and found that their social communication improved.

As Moola et al. (2014) report, therapeutic summer camps have been proposed as an effective intervention for children whom may or may not suffer from chronic illness or disability because camp can address a variety of underlying psychosocial difficulties and improve QOL. Occupational justice is built on the premise that the role of society includes the provisions of equal opportunities for all (Braveman \& Suarez-Balcazar, 2009). According to Jakobsen (2004), individuals with disabilities and other minority groups often face societal barriers and obstacles in the pursuit of occupational justice. Segregated summer camps that lack inclusion deny youth with disabilities meaningful play, leisure, and skill development (Braveman \& Suarez-Balcazar, 2009).

Creating an environment linked with adaptations may allow youth to engage in meaningful play with peers (Knebel, 2018). The authors Wilson et al. (2017) profess that youth who enjoy physical activity at camp are motivated to engage and are more physically active, which leads to improved wellness.

Programs that apply a client-centered approach and make adaptations to the environment are employing the Ecology of Human Performance (EHP) model (Dunn, Brown, \& McGuigan, 1994). The adapt/modify strategy within the EHP model may be applied through physical modification (i.e., assistive devices or ramps) and adaptations to improve task performance for the participants (Dunn et al., 1994). Other environmental adaptations to provide a more inclusive context may include adaptive rock climbing gear, a pool ramp, or increased paved pathways (Melikechi, 2015, p. 49), which could increase youth participation and occupational 
performance. Increasing environmental adaptations will allow children of varying abilities to benefit from positive youth development through the social network of camp (Snider \& Farmer, 2017). The potential for positive implementation and change is monumental because available literature reports camp has a positive effect on youth into adulthood (Melikechi, 2015; Snider \& Farmer, 2017).

Professional development is pivotal for camp staff to feel empowered in their work environment and can be structured into camp training (Kendellen, Camire, Bean, and Forneris, 2016). For example, shadowing a more experienced camp employee leads to improved communication skills and developing confidence (Kendellen et al., 2016). Creating and promoting a more inclusive environment for youth to engage in meaningful occupations at camp can positively impact their ability to participate and feel comfortable with peers (McCarthy, 2015). Play is the primary occupation of childhood, and the findings support fun and play in the outdoors are critical to healthy youth development (Moola et al., 2014). Play can influence a child's perspective on camp, promoting less isolation in an environment where everyone is the "same" and has the capacity to form meaningful connections with peers (Moola et al., 2014).

As an emerging practice area for OT, residential youth camp is a non-traditional setting where youth can use nature to connect with peers, learn social skills, and, most importantly, engage in meaningful play. Occupational therapy-led nature camps and outdoor therapeutic programs are both designed by OT to integrate interventions into summer camp routines. However, their existence is limited. Occupational therapists can create therapeutic programming with intervention purposefully imbued throughout an inclusive context with typically developing peers. The resulting summer camp programs will promote the confidence, connection, 
development of friendships, and increased independence with activities of daily living. Together, these are the building blocks of positive youth development.

\section{Project Objectives}

1. Identify the inclusion needs of a residential youth camp through observation and participation in the activities.

2. Identify the needs of residential youth camp through a literature search.

3. List common residential youth camp inclusion methods and delivery approaches.

4. Evaluate the strengths and limitations of residential youth camp inclusion through on-site experience and observation.

5. Compare success factors in residential youth camp programming from the literature search and analyze feasibility to implement at a residential youth camp.

6. Propose recommendations and train staff to increase knowledge and awareness of inclusion needs.

\section{Operational Definitions}

Environmental Analysis is defined as examining the context in which an occupation or activity occur to understand how elements support learning and performance. Identified barriers build on supports through modification and adaptations (AOTA, 2014).

Occupational Justice is defined as all individuals have an equal and inclusive opportunity to participate in everyday occupations regardless of age, ability, gender, social class, or other differences (based on the work of Nilsson \& Townsend, 2010).

Positive Youth Development is defined as an approach to working with youth that highlights building on youth strengths and providing supports and opportunities that will encourage them to 
accomplish goals and transition to adulthood in a productive, healthy manner (based on the work of Halsall et al., 2016).

\section{Assumptions, Limitations, and Delimitations}

This project operated under several assumptions. The first was that all camp participants had occupational needs or limitations that hindered their participation in the camp experience. Zwicker et al. (2015) indicate that children with developmental coordination disorder suffer from poor motor abilities, which negatively impact their participation in physical activity. The next assumption was that many of the children with disabilities were lacking in social engagement and felt secluded. Moola et al. (2014) report that children with disabilities often feel isolated and lack social interactions when compared with typically developing peers. The third assumption was that most of the youth would have a positive experience engaging in camp. Snider and Farmer (2017) state that summer camp enriches lives through positive experiences. Finally, there was an assumption that the facility would be receptive to and implement the recommended changes to enhance programming.

The limitations of this program were the seasonal timing (winter) weather was a barrier for specific outdoor activities (such as rock climbing, hiking, and horseback riding). The most important limitation was available hours to observe the program in action, including its staff and participants. Unfortunately, due to the COVID-19 Pandemic, the facility and all California schools were temporarily closed, which abruptly hindered the completion of this project. Although I was able to conduct the training, I was not able to see the impact of the in-service and the proposed recommendations.

One delimitation includes the selection of a residential camp for the capstone experience as well as youth camp participants who live within 100 miles and range in age from seven to 
seventeen years old. Selecting a residential youth camp was a limiting factor to the findings because the OT student was unable to access the inclusion methods of day camps. Day camps are presented with a different culture and may provide more consistent staff versus seasonal residential camp (Purvis et al., 2007).

\section{Chapter II: Literature Review}

This chapter will present the literature review for this capstone project. The process focused on how inclusion, as supported by OTs, can benefit special needs students in a residential camp setting. Relevant topics included: positive youth development, positive benefits of inclusive camps, and the emerging practice area for OTs.

\section{Positive Impact on Youth Development}

Positive Youth Development (PYD) is established on the belief that successful development does not occur from the absence of risky behavior, but from the presence of positive attributes that empower youth to reach their full potential (Merryman, Mezei, Bush, \& Weinstein, 2012). Halsall et al. (2016) identify that positive youth development has been a fundamental theme that has emerged through the literature, offering autonomy in a supportive environment where youth can build positive relationships. Play is the primary occupation of childhood (Lyon, 2018; Walker et al., 2010). The authors Moola et al. (2014) indicate that fun and play in the outdoors are pivotal to healthy youth development. Play has the opportunity to influence a child's perspective on camp, promoting less isolation in an environment where everyone's the "same" and has the potential to form new friendships (Moola et al., 2014). Wilson 
et al. (2017) report youth who enjoy physical activity at camp are motivated to engage and are more physically active.

Snider and Farmer (2017) found that summer camp can enrich the lives of youth through positive experiences, which have been demonstrated to have long-term effects. Kendellen et al. (2016) profess that "rookie" staff who shadowed a veteran camp employee enhanced their communication skills and confidence. This experience facilitated staff members' leadership development, which also promoted positive youth development.

\section{Positive Impact of Camp on Youth with Disabilities}

One of the objectives of residential camp experiences is to create a sense of community among campers, and disability-specific camps set the stage for belonging and social acceptance (Devine, Piatt, \& Dawson, 2015). However, Reinders, Redquest, Fletcher, Schneider, and Bryden (2019) indicate that children with special needs face barriers when accessing summer camps due to inadequate program accessibility. Only two percent of American Camp Association camps exclusively serve youth with disabilities (Shefter et al., 2017), while seven percent are inclusive (Hall, Dunlap, Causton-Theoharis, \& Theohari, 2019). The American Camp Association is the largest accrediting organization of summer camps in the US (McCarthy, 2015).

Papaioannou, Evaggelinou, Barkoukis, and Blockfound (2013) reveal that disabilityspecific camps are built on the principles of therapeutic recreation and are prime contexts to study the perceptions of social acceptance. Disability-specific camps provide youth a chance to explore and to promote a sense of who they are in an environment abundant in peer support (Dahlbeck \& Lightsey, 2008). This experience gives them the insight to better approach the social and functional challenges they face in mainstream society (Dahlbeck \& Lightsey, 2008). 
Structuring leadership development into camp staff training is pivotal to promote positive youth development in children with disabilities (Kendellen et al., 2016). Reinders et al. (2019) indicate that creative arts offer psychological benefits when explored in an inclusive, safe environment, such as summer camp. Bandino, Garfinkle, Zickefoose, and Hsieh (2014) report that activities within disability-specific camps are adapted to accommodate the special needs of each camper, providing the just-right challenge that ensures optimal success.

\section{The Emerging Role of Occupational Therapy in Adaptive Summer Camps}

The emerging role of OT in summer camps positively impacts the lives of youth because OT brings environmental adaptations and breaks down barriers that impede engagement and the formation of meaningful relationships (Hendricks \& Toth-Cohen, 2018). Schoen, Miller, Hampton, and Kanics (2014) identify that outdoor play environments are an expansion of the classroom that stimulate gross and fine motor skills as well as support the development of social and emotional skills. Jeffery and Wilson (2017) discuss the positive effects of OT meshed with what they term adventure therapy, which can be described as using outdoor adventure-based activities to promote change on a psychosocial or psychological level, specifically with youth. Hellman and Gwinn (2017) report semi-structured camp activities are designed to promote teamwork, creative thinking, problem-solving, and build group trust. Occupational therapists have expertise in activity sequencing, grading and adapting to integrate adventure therapy into a camp context (Jeffery \& Wilson, 2017). Together, these studies reinforce OT's ability to create a welcoming, inclusive environment within a summer camp, thereby promoting a successful experience for students with special needs. 


\section{Literature Review Summary}

Three themes emerged from the literature review: inclusion has a positive impact on youth development, on camps for youth with disabilities, and is the foundation for the emerging role of OT in adaptive camps. These themes promote the use of activity modification and adaptations to create inclusive residential youth camp environments and enrich the lives of youth.

\section{Chapter III: Project Description}

Moola et al. (2014) reported that creating a more inclusive environment is essential for the well-being of all people. This capstone proposal pursued to assess the need for inclusivity and proposed recommendations for Pathfinder Ranch, a residential summer camp. A needs assessment, including parents' perspectives, was used to identify the barriers that limit participation for the population at Pathfinder Ranch.

The process included observations of current programming, interviews with staff, and an evaluation of current resources to complete the needs assessment. At the start of the project, staff were introduced to the project procedures and goals, and an open discussion took place to answer any remaining questions.

Observations of current programming and a layout of the facility identified areas where adaptations could create a more inclusive environment. The information gathered helped to recognize funding gaps and provided an opportunity to propose recommendations. Experiencing the activities led by camp staff, built rapport and understanding from a participant's perspective.

\section{Participants}

All of the participants were drawn from the pool of camp staff at Pathfinder Ranch as well as parents of participants and teacher chaperones. Approval for staff interviews was 
obtained from the program director of Pathfinder Ranch. Parents of participants with disabilities were invited to participate and gave their perceptions, as they are stakeholders in the organization. The participants were scheduled for interviews a week after initial contact. Semistructured interviews lasted for 20 to 30 minutes, and notes were taken during the interviews for later analysis (Snider \& Farmer, 2017). Semi-structured style and open-ended questions helped to gain a better understanding of participants' perceptions of inclusion and identified environmental strengths and limitations. Example of questions used for staff interviews may include: What type of adaptive equipment does this facility use and do you know how to operate it? Do you feel this facility is inclusive why or why not? How often do you work with special needs groups? What environmental barriers can you identify for a person with a disability? What changes would you like to see to promote inclusivity?

\section{Project Design}

The duration of the project was eleven weeks. The first two weeks were spent observing and volunteering at an outside camp's facilities, which offered a broad spectrum of adaptive and inclusive activities for youth. During this time, observation of facility adaptations and activity engagement were recorded in a notebook to generate ideas for Pathfinder Ranch.

Then during weeks three to seven, the OT student transitioned to Pathfinder Ranch in Mountain Center, California. The OT student observed the facility, staff policies, and camp culture. She also participated in the activities, which built rapport and provided the opportunity to give staff real-time feedback on inclusion techniques (Snider \& Farmer, 2017). The OT student used a notebook to document typical daily procedures, adaptive equipment used, how the participants seemed to interact with the current environment, and barriers observed. After daily observations, reflective journaling elicited program strengths, limitations, and adaptation 
recommendations. An analysis of current adaptive equipment and environmental modifications took place from weeks eight to eleven and were documented in a notebook. Recommended changes, enhancements, and additional funding sources for the facility were proposed to the program director. The OT student provided training and discussion afterward; however, the COVID-19 Pandemic did not allow for the observation of program implementation.

\section{Envisioned Next Steps}

The envisioned next steps for the OT student include collaboration with an OT that specializes in hipportheray and the exploration of other inclusive residential camps. The stakeholders (management and staff at Pathfinder Ranch) could benefit from partnering with an OT who specializes in hippotherapy due to their vast experience and its application to Pathfinder Ranch. Occupational therapists who specialize in hippotherapy use horses along with therapeutic techniques to promote occupational engagement, social participation, and routine in a therapy context (Ingold, 2017).

Horses play a significant role at Pathfinder Ranch, and networking with a hippotherapist may provide a different lens on programming adaptations. Equine-assisted therapies have been utilized in clinical settings to treat ASD, attention-deficit/hyperactivity disorder, post-traumatic stress disorder, and other physical and psychological conditions (White, Zippel, \& Kumar, 2020). White et al. (2020) identified how the application of equine-assisted therapies supported socialization, psychotherapy, and relaxation. Furthermore, they noted hippotherapy could be applied in different cultural contexts regardless of age or gender. Following the completion of the project, the stakeholder could expand their knowledge of techniques through online inclusion training offered through an internationally distinguished non-profit, such as Kids Included 
Together. Site visits to inclusive residential camps would provide the stakeholder with additional ideas to support involvement for all.

\section{Chapter IV: Results and Analysis}

Upon completion of the needs assessment at Pathfinder Ranch in Mountain Center, California, many results outlined the inclusion and OT needs of the camp facility and the special needs population. The needs assessment included observation of and participation in camp programming, a Pathfinder Ranch staff survey, semi-structured interviews with staff, special needs teachers, and parents of participants with disabilities. These results were applied in a staff in-service training session. Approximately 200 youth participants were observed over 11 weeks at Pathfinder Ranch while they engaged in outdoor education and activities within the camp environment. The OT student actively participated in outdoor education classes to observe current inclusion methods and use of adaptive equipment while providing immediate feedback on inclusion to support staff working with diverse students.

The online staff survey included 11 open and close-ended questions focused on participants' perceptions of inclusion, environmental strengths, and limitations and needs at Pathfinder Ranch (see Appendix A). The survey was introduced at the start of project and was presented at week 7 via email to the camp staff. Participation in the survey was voluntary and completed by all 11 outdoor education staff. A follow up survey was unable to be given due to the COVID-19 Pandemic and the abrupt closing of Pathfinder Ranch. However, at the end of the survey the staff was able to provide feedback and suggestions to improve the delivery of material. 
The questions included:

1) What type of adaptive equipment does Pathfinder Ranch use, and do you know how to operate it?

2) Do you feel this facility is inclusive?

3) What supports can you identify which may promote inclusion at Pathfinder Ranch?

4) What barriers or limitations can you identify at Pathfinder Ranch that may hinder inclusion?

5) What activities do you find to be the most challenging when including all participants?

6) What are some strategies you have used to overcome challenges with inclusion?

In the survey results, four themes related to inclusion emerged:

1) The desire for more frequent training on inclusion methods and adaptive gear;

2) Challenging terrain;

3) More open discussions on inclusion; and

4) Increased knowledge on participants' accommodations to promote success within the camp setting.

\section{Theme 1: Increase Training on Inclusion Methods}

The participants identified the need for more robust inclusion training that would include a variety of methods with specific lesson plans and activities. The outdoor education staff stated a manual with inclusion techniques for each activity would assist their planning and help to incorporate all students. Further, although the facility also has a variety of adaptive gear for rock climbing, archery, canoeing, and horseback riding, the majority of the staff stated they were unaware of the equipment and how to properly operate it: "I do not feel comfortable using the 
adaptive climbing gear" (Camp Staff \#4); "Need more staff to utilize the specialized equipment, but also need additional training on things like the adaptive climbing gear" (Camp Staff \#5); and "Courses like Energy have selected activities that I find hard to have the students do at their own comfort level. I could benefit from learning how others adapt these activities" (Camp Staff \#10). One staff member clarified:

The camp management team identified a lack of time to provide training on adaptive equipment, and didn't feel training was a high priority, as the equipment is not used often: Limited time for staff training on the wide variety of needs staff may encounter and on how to identify likely needs based on observations and without trying to make a diagnosis (since schools/parents do not always inform us of children's disabilities and developmental differences. (Camp Staff \#3)

\section{Theme 2: Challenging and Diverse Terrain}

The high elevation environment was discovered to be a challenging area to promote inclusion within all activities. Diverse terrain was also problematic. The facility is on a sprawling parcel backed up to the Cleveland National Forest and includes compact, stable ground, rocky paths, sandy washes, and meadows. Staff participants in the survey, children, and chaperones identified specific activities where they found the environment to be the most challenging. One teacher reported: "My students have never been on a hike and the rocky terrain is especially challenging for the students with low muscle tone or cerebral palsy" (Teacher \#3).

All of the staff $(100 \%$ or $11 / 11)$ identified "environment" as the most challenging factor for inclusive activities: "Ethnobotany (hiking required) is hard for students with mobility challenges" (Camp Staff \#5); "I think there could be more programming areas that are wheelchair accessible" (Camp Staff \#6); "Hikes are the most challenging, whether it's with 
including kids with mental, emotional, or physical differences that may require adaptation" (Camp Staff \#7); and "Including campers with physical limitations on hikes is challenging because of the terrain and time limits" (Camp Staff \#11). These comments identified the need for environmental adaptations. Additional funding and labor sources, such as grants or volunteer groups, could be identified to assist in the necessary modifications.

\section{Theme 3: Increase Discussion on Inclusion}

The staff expressed the need for open discussions on inclusion methods and techniques to increase ideas and apply them within the programming. The survey results pinpointed that $27.3 \%$ (3 staff members) had worked with 0-3 children with different needs. They commented: "We don't talk about what inclusion means or how to put it into practice often enough" (Camp Staff \#7); and 'I find it challenging when a student doesn't want to be seen using adaptive rockclimbing equipment” (Camp Staff \#2).

The staff also recognized their coworkers as potential resources, as 54.6\% (6 staff members) had worked with more than 30 special needs youth in camp settings: "My supervisor is a great resource for providing adaptive solution to recreational activities. Other naturalists can be great to brainstorm with and offer suggestions for adapting specific classes" (Camp Staff \#1). Furthermore, seasoned staff could provide consistent coaching to rookie staff and collaborate for in-service trainings.

\section{Theme 4: Increase Knowledge of Students' Needs}

Throughout conversations during outdoor activities, all the staff indicated that having more detailed information on each student would help them feel better equipped when planning lessons. Without additional knowledge of students, staff members reported feeling unprepared and unsure of how to best support the students in an academic or extracurricular activity: "Team 
Challenge can be difficult to plan when caregivers are not clear about different physical abilities or challenges" (Camp Staff \#1). The staff are not offered extra information, such as special needs outside of allergies or if the child participates in a special day class.

The OT student collaborated with special education teachers and parent chaperones to implement best practices when working directly with students. This also provided an opportunity to establish rapport, become acquainted with the student's needs, and learn inclusive techniques. Gathering pertinent information on the student provided the stakeholder with a holistic view of the child and gave an opportunity to focus on deficits within instrumental activities of daily living (IADLs). The OT student was able to support the outdoor education staff by suggesting modification within the activities, to create the "just right" challenge.

The students were then observed collaborating with peers and completing adapted and modified tasks while engaging in an inclusive activity. For example, during the Fresh Water Ecology class, there was one student whom was hard of hearing, one with low vision, and another with mobility challenges. The OT student suggested adapting the activity by bringing a water sample to the table along with the visual identification card to allow for improved participation and social engagement. Similar to the findings from Hellman and Gwinn (2017), the students used teamwork to observe similar macroinvertebrates as their peers by the lake but in an adapted context. Students reported: "This is so interesting! I love this activity!" (Student \#1); “Wow! I found the same invertebrate that's on this paper!" (Student \#2). "Sitting at this table makes it easy for us to find these organisms" (Student \#3).

The outdoor education staff reported: "The new techniques allowed me to ensure that all the students were able to participate at their own comfort level” (Camp Staff \#2); "After utilizing the new skills, I was able to see my group of students grow as a cohesive unit during team 
challenge" (Camp Staff \#1). In a school setting, one of the roles of an OT is to collaborate with educators to modify or adapt the environment, fostering success in meaningful occupations. The OT student observed the camp staff, benefiting from feedback as evidenced by the activities being modified or adapted to fit the group's needs and participation from all.

Caregivers are required to fill out forms for student participants before arriving at camp to provide basic information. The forms provide upper management with a general idea about the student participant, including allergies and emergency contact. However, staff reported that the responses are often vague and lack critical information such as behavior concerns, academic accommodations, and hobbies: "We get limited information on how to support each student" (Camp Staff \#7); and "I wish the parents would provide more details on how to help their child adapt to being away from home, especially if their child has any limitations" (Camp Staff \#9).

\section{Findings from Semi-Structured Interviews with Staff and Parents}

The semi-structured interviews with staff, schoolteachers, and parents explored the barriers within the camp environment and transitions from an academic setting to an overnight camp.

The questions used included:

1) How could the camp staff best support the student?

2) How has this transition been away from home?

3) What barriers in this environment can you identify for the student?

4) What is their learning style?

5) What is the best method of communication?

6) Do they typically interact with peers in their designated group?

7) Who would be the best peer partner in their group? 
8) How do they do with verbal instruction/direction?

9) What is the best method for redirection?

The interviews provided key data for the OT student on specific inclusion methods to best suit each camper as well as a variety of techniques. The inclusion methods were implemented with the direct support of the special education teacher and then taught to the outdoor education staff.

The parents reported that camp has given their children opportunities to learn life skills and has challenged them outside of their comfort zones: "This is the first time I have ever seen him get ready for the day without having to be reminded numerous times" (Parent \#1); and "This morning, she was dressed and had her water bottle filled before the bell rang. At home, we struggle with time management” (Parent \#2).

From the one special ed teacher's perspective:

Science camp is about these kids learning to get dressed, put on their own damn socks, shower, and take care of themselves. This is the first time many have been away from home and their parents are here to do everything for them. (Teacher \#1)

The OT student observed consistency throughout the weeks, with 1 or 2 outdoor education staff leading each group. The consistency established a routine that the students could rely on and also helped to build staff-student rapport.

\section{In-Service}

The OT student created and led an in-service for the outdoor education staff. In order to reflect camp culture and to encourage participation, which was reported as an issue in past trainings, the staff participated in a competitive inclusion trivia game and a focus group (see Appendix B). As the teams took turns, the group was observed openly discussing inclusion 
techniques and what had worked this past season with different groups. All of the staff (100\% or 11/11) identified the in-service to be "beneficial and valuable" in generating new inclusive techniques.

\section{Chapter V: Summary, Discussion, and Conclusion}

\section{Summary}

The objective of this capstone project was to complete a needs assessment to identify the supporting role of OT in adapting a summer camp for increased inclusion. The OT student observed programming, engaged in activities with participants, and completed interviews. The resulting data was used to create an in-service and to provide program recommendations on fostering an inclusive environment.

The findings relate to the assumptions in which when camp activities are modified or adapted to fit a group's needs, it promotes inclusion and creates enjoyable experiences where all can benefit. These findings from McCarthy (2015); Moola et al. (2014); and Walker et al. (2010), confirm the theory of creating an inclusive environment with meaningful occupations will increase social participation and engagement which are the building blocks of positive youth development. Following the EHP model (Dunn et al. (1994), allowed the OT student to create person-centered adaptations and modification which were observed to increase task performance and occupational performance leading to an increased engagement in the camp activities.

\section{Discussion}

Occupational therapy plays a vital role in advocating and promoting inclusion to meet the needs of all children (Merryman et al., 2012). The needs assessment of the camp setting identified three focus areas: limited experience of staff, high anxiety of parents, and variable 
physical terrain. These were determined to negatively impact occupational performance. After completing the needs assessment, the OT student proposed recommendations (see Appendix D) to promote a more inclusive environment.

\section{Current Pathfinder Ranch Inclusion Strengths Observed}

- Continue to stay informed on inclusive techniques and best practices through current literature, conferences, and organizations such as American Camp Association.

- Continue to train new staff on inclusive techniques.

- Continue to endorse open conversations on inclusion by staff, as this was observed to provide support and was identified as valuable in the staff survey.

- Continue to provide direct support to youth with special needs and to encourage staff to modify or adapt activities as needed.

\section{Recommendations for Pathfinder Ranch}

- Pair experienced staff with rookie staff when presenting in-services on inclusive topics to encourage collaboration, coaching, advance knowledge, and boost confidence.

- Encourage all staff to complete an online inclusion training through Kids Included Together (www.kit.org), an organization which is nationally known for their high quality inclusion training.

- Examine the camp participant intake form to identify areas for improvement in providing additional pertinent information to best support the student.

- Following the Family Educational Rights and Privacy Act (FERPA) provide pertinent information to outdoor education staff which may support their lesson planning and assist with building rapport.

- Allow outdoor education staff to collaborate with the special ed teachers or caregiver 
chaperones to gain a better understanding of the child's accommodation needs to promote success and the just-right challenge.

- Introduce staff to the inclusion tips listed in Pathfinder Ranch's “Activities and Concepts Lesson Plan" document (see Appendix C) to advance their ability to promote inclusion when working with diverse populations and to reduce lesson planning time.

\section{Lack of Staff with Experience Working with Special Needs Youth}

The literature regularly identified that segregated special needs camps were often challenged by the limited number of experienced staff (Braveman \& Suarez-Balcazar, 2009). The survey results of this project echoed those findings. Specifically, four out of eleven (36\% of) staff had experience working at segregated camps (see Figure 1).

Have you ever worked at a segregated camp for youth with disabilities?

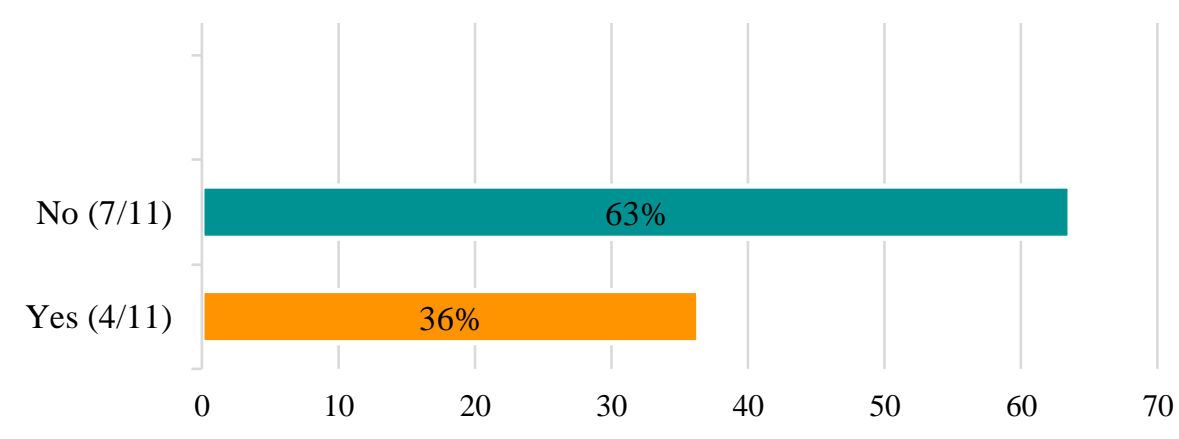

Figure 1. Survey Question Seven responses.

Their lack of experience contributed to participants' lack of confidence in working with kids with different needs (see Figure 2). 


\section{Confidence Working with Kids with Different Needs}

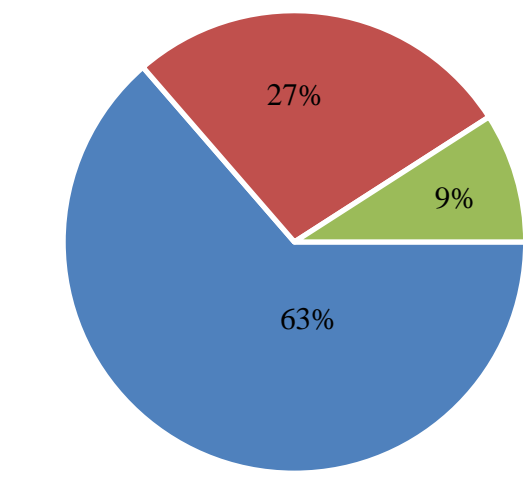

- Agree - Strongly Agree $\quad$ - Disagree

Figure 2. Survey Question Two responses.

For example, staff members reported: "I'm just not sure how to modify or adapt my orienteering class so that all the students will be able to participate. I could really use the [OT student's] guidance" (Camp Staff \#2); and "I have never worked with special needs kids before. I feel more confident knowing that I will have [the OT student's] support while working with this group” (Camp Staff \#5). These findings are consistent with Kendellen et al. (2016), which identifies seasoned staff can mentor those with less experience, elevating confidence, and increasing skill sets.

\section{Parent Anxiety as a Barrier}

The project findings were consistent with those from the literature, as McCarthy (2015) and Moola et al. (2014) indicated the anxiety of parents of children with disabilities was a barrier to attending camp and they benefited from teacher and staff reassurance.

In this project, one special ed teacher reported: "His parents gave me a hard no when they first heard about camp. I explained that I have been working with him for three years and I can handle his needs" (Teacher \#1). "Both of their parents were concerned about negative behavior, but as the school's behaviorist, I assured them it would be handled appropriately" (School 
Behaviorist \#1). Consistent with the literature, OT can support parents' concerns by educating and consulting on adaptive modifications that promote inclusion at camp (Moola et al., 2014).

The OT student observed numerous teachers updating parents via text message with images of their child engaging in meaningful occupations and meeting personal goals. Consistent with the data from McCarthy (2015), as a result of the child being able to attend camp, she achieved a personal goal and gained self-confidence along with peer support. For example, one child with limited verbal communication expressed her goal in reaching the top of the rock wall. After the climb she was observed smiling and high-fiving peers. She reported: "I'm proud" (Student 3).

\section{Environmental Limitations}

The OT student observed environmental barriers with hindered participation and occupational performance among the youth participants. Consistent with the literature, Melikechi (2015) and Snider and Farmer (2017) identified environmental barriers, such as terrain, as limiting factors in task performance. In the survey results, 90.9\% (10 out of 11$)$ participants identified hiking as the occupation most impacted by the environment (see Figure 3).

The Occupation Most Impacted by the Environment

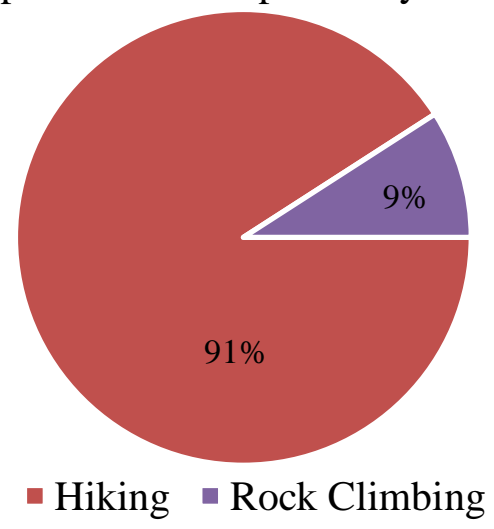

Figure 3. Survey Question Six Responses. 
They noted hiking had limited engagement and social participation. The staff identified three ways to modify or adapt the activity for groups with special needs: 1 . Shorten the route, 2. Hike a paved trail, and 3. Provide more rest breaks. After providing recommendations to the staff, the OT student observed these accommodations in action. Further, the staff brainstormed different routes to accommodate specific needs. In this case, the EHP model provided a foundation to address a problem: terrain. The components of EHP were used to promote a clientcentered approach, modify to improve task performance, and support a more inclusive environment (Dunn et al., 1994).

\section{Limitations and Barriers}

The limitations of this project were the seasonal timing (winter) weather and the available hours to observe the program in action involving the staff and participants. The cold, wet weather was a barrier for specific outdoor activities (such as rock climbing, hiking, horseback riding, and canoeing). Another barrier to the project was the low number of survey participants secondary to the small employee population. The COVID-19 Pandemic temporarily closed all schools and all gatherings of individuals, leading to the abrupt cancellation of camp. This made competing the follow up survey, observation, and implementation of recommendations impossible within the given capstone project timeline.

The in-service training was conducted, but the OT student was not able to see the impact of the training and the proposed recommendations (see Appendix D). However, all of the feedback shared via survey and provided in person to the OT student was positive in nature. Staff members indicated their need and desire for OT support in this residential youth camp setting: "It was helpful to have support while working with my diverse group and learn how to modify and adapt activities on the spot. It was easier than expected. I could use what I learned in many camp 
activities" (Camp Staff \#3); "I never thought to put the water specimen on the table to accommodate kids with orthotic conditions, hearing or visual deficits. But it was so neat to see them all engage in the activity!" (Camp Staff \#5); and "I wish [the OT student] could have stayed longer because it was extremely helpful to learn new techniques and be given immediate feedback" (Camp Staff \#6). Lastly, information from the observations and interviews indicated the population had a limited understanding and knowledge of the role of OT. Therefore, explanations were provided to camp staff, students, and their chaperones. On the other hand, teachers and parents did demonstrate knowledge of OT and its benefits when sharing their positive experiences working directly with occupational therapists.

\section{Implications for Occupational Therapy}

Occupational therapy has an expert understanding of individuals engaging in meaningful occupations and ways in which the environment supports or limits participation (Braveman \& Suarez-Balcazar, 2009; Moola et al., 2014). This capstone project supports the role of OT through increased inclusion within a residential camp, as evidenced by the positive feedback from Pathfinder Ranch staff as well as the participants engaging in meaningful, inclusive tasks. Pathfinder Ranch could benefit from collaborating with an OT to promote inclusion to support activity modification and provide feedback during lesson planning.

Occupational therapy has a unique understanding of adapting activities and environments to match task demands (AOTA, 2014), which could assist the staff in creating inclusivity (Braveman \& Suarez-Balcazar, 2009). The OT literature supports offering recommendations to increase social participation, which could have positive long-term effects on the peer bonds formed (Melikechi, 2015; Snider \& Farmer, 2017). 


\section{Future Research Studies}

There is a clear argument for the use of OT as it relates to occupational performance, program development, and activity adaptation. Specifically, OT could create and adapt camp programming to provide a more inclusive environment. Future research could enhance the strength of the survey results through increased distribution to other Pathfinder Ranch staff and other residential camps.

Additionally, observing traditional summer camp at Pathfinder Ranch could also provide fundamental observations that could document the need for OT to consult in the youth camp setting to promote inclusion. Furthermore, future research could examine the camp participant intake form to identify areas for improvement in providing additional pertinent information to best support the student:

I've noticed that one of my students is not able to focus or follow along in the same manner as the others, but I wasn't given any additional information. This makes it really hard to know how I can best support them. (Camp Staff \#4)

\section{Conclusion}

Creating an inclusive environment where people with and without disabilities have an equal opportunity to engage in meaningful occupations is a core belief of the OT profession (Knebel, 2018). Occupational therapists can use innovative approaches to create environments that sustain inclusion. Occupational therapy is an emerging area of practice throughout residential youth camps in the US (Hendricks \& Toth-Cohen, 2018). However, there is limited research connecting their role in promoting inclusion in these settings (Halsall et al., 2016). This project identified occupation-based performance issues, including limited social engagement and lack of peer support for youth who were not typically integrated with their peers. This suggested 
the field of occupational therapy can expand its role in the emerging practice area of residential youth camps by supporting inclusion. Enhancing inclusion supports the building blocks to positive youth development by building confidence, connection, development of friendships, and increased independence with activities of daily living. 


\section{References}

American Occupational Therapy Association. (2014). Occupational therapy practice framework: Domain and process (3rd ed.). American Journal of Occupational Therapy, 68(Suppl. 1), S1-S48. https://doi.org/10.5014/ajot.2014.682006

Bandino, M. L., Garfinkle, R. A., Zickefoose, B. A., \& Hsieh, D. T. (2014). Epilepsy at a summer camp for children and young adults with developmental disabilities: A 3-year experience. Military Medicine, 179(1), 105-110. https://doi.org/10.7205/MILMED-D-13$\underline{00304}$

Braveman, B., \& Suarez-Balcazar, Y. (2009). Social justice and resource utilization in a community-based organization: A case illustration of the role of the occupational therapist. American Journal of Occupational Therapy, 63(1), 13-24.

Dahlbeck, D. T., \& Lightsey, O. R. (2008). Generalized self-efficacy, coping, and self-esteem as predictors of psychological adjustment among children with disabilities or chronic illnesses. Children's Health Care, 37(4), 293-315. https://doi.org/10.1080/02739610802437509

Devine, M. A., Piatt, J., \& Dawson, S. (2015). The role of a disability-specific camp in promoting social acceptance and quality of life for youth with hearing impairments. Therapeutic Recreation Journal, 49(4), 293-309. http://dx.doi.org/10.18666/TRJ-2015$\underline{\text { V49-I4-6240 }}$

Dunn, W., Brown, C., \& McGuigan, A. (1994). The Ecology of Human Performance: A framework for considering the effect of context. American Journal of Occupational Therapy, 48(7), 595-607. https://doi.org/10.5014/ajot.48.7.595 
Feenstra, J. (2015). Summer camp and positive youth development: Program with Romanian youth. The Physical Educator, 72(5), 185-199.

Hall, A., Dunlap, T., Causton-Theoharis, J., \& Theohari, G. (2019, January 18). The power of the inclusive camp experience. Retrieved from https://www.acacamps.org/resourcelibrary/camping-magazine/power-inclusive-camp-experience.

Halsall, T., Kendellen, K., Bean, C., \& Forneris, T. (2016). Facilitating positive youth development through residential camp: Exploring perceived characteristics of effective camp counselors and strategies for youth engagement. Journal of Park and Recreation Administration, 34(4), 20-35. https://doi.org/10.18666/JPRA-2016-V34-I4-7273

Hanscom, A., \& Schoen, S. (2014). Using occupational therapy principles in developing nature camp for all children. American Journal of Occupational Therapy, 37(4), 1.

Harper, N. J. (2017). Wilderness therapy, therapeutic camping and adventure education in child and youth care literature: A scoping review. Children and Youth Services Review, 83, 6879. https://doi.org/10.1016/j.childyouth.2017.10.030

Hellman, C. M., \& Gwinn, C. (2017). Camp HOPE as an intervention for children exposed to domestic violence: A program evaluation of hope, and strength of character. Child and Adolescent Social Work Journal, 34(3), 269-276. https://doi.org/10.1007/s10560-016$\underline{0460-6}$

Hendricks, F., \& Toth-Cohen, S. (2018). Perceptions about authentic leadership development: South African occupational therapy students' camp experience. Occupational Therapy International, 2018, 1-9. https://doi.org/10.1155/2018/1587906 
Ingold, S. (2017, December 13). Not horsing around: Therapy with horses at the red barn [Blog post]. Retrieved from https://www.apr.org/post/best-lifestyle-feature-not-horsing-aroundtherapy-horses-red-barn\#stream/0

Jakobsen, K. (2004). If work doesn’t work: How to enable occupational justice. Journal of Occupational Science, 11(3), 125-134. https://doi.org/10.1080/14427591.2004.9686540

Jeffery, H., \& Wilson, L. (2017). New Zealand occupational therapists' use of adventure therapy in mental health practice. New Zealand Journal of Occupational Therapy, 64(1), 32-38.

Kendellen, K., Camire, M., Bean, C. N., \& Forneris, T. (2016). Facilitators and barriers to leadership development at a Canadian residential summer camp. Journal of Park and Recreation Administration, 34(4), 36-50. https://doi.org/10.18666/JPRA-2016-V34-I4$\underline{6514}$

Knebel, B. (2018, March 15). The role of occupational therapy in inclusion [Blog post]. Retrieved from https://blogs.missouristate.edu/bearpower/2018/03/15/the-role-ofoccupational-therapy-in-inclusion/

Lyon, S. (2018). OT Potential: Use your OT skills to get kids outside: An introduction to TimberNook. Retrieved from https://otpotential.com/blog/ot-skills-and-timbernook

McCarthy, A. (2015). Summer camp for children and adolescents with chronic conditions. Pediatric Nursing, 41(5), 245-250.

Melikechi, L. (2015). A camp for everyone: A guide to including children of all abilities in summer camp programs. DE: United Cerebral Palsy of Delaware, Inc. 
Merryman, M., Mezei, A., Bush, J. A., \& Weinstein, M. (2012). The effects of a summer camp experience on factors of resilience in at-risk youth. The Open Journal of Occupational Therapy, I(1). https://doi.org/10.15453/2168-6408.1016

Moola, F. J., Faulkner, G. E. J., White, L., \& Kirsh, J. A. (2014). The psychological and social impact of camp for children with chronic illnesses: A systematic review update: Camps for sick children. Child: Care, Health and Development, 40(5), 615-631. https://doi.org/10.1111/cch.12114

Nilsson, I., \& Townsend, E. (2010). Occupational Justice: Bridging theory and practice. Scandinavian Journal of Occupational Therapy, 17(1), 57-63. https://doi.org/10.3109/11038120903287182

Papaioannou, C., Evaggelinou, C., Barkoukis, V., \& Block, M. (2013). Disability awareness program in a summer camp. European Journal of Adapted Physical Activity, 6(2), 19-28.

Purvis, K., Cross, D., Federici, R., Johnson, D., \& McKenzie, L. (2007). The Hope Connection: A therapeutic summer day camp for adopted and at-risk children with special socioemotional needs. Adoption \& Fostering, 31(4), 38-48.

Reinders, N., Redquest, B., Fletcher, P., Schneider, M., \& Bryden, P. (2019). Arts express: An adapted creative arts camp in Waterloo, Ontario. Palaestra, 33(1), 40-45.

Schoen, S., Miller, L., Hampton, S., \& Kanics, I. (2014). Occupational therapy in natural settings: Using playgrounds. The American Occupational Therapy Association, 37(3), 14. 
Snider, C. L., \& Farmer, J. R. (2017). Impacts of a southern Indiana summer camp: Adult reflections on childhood experiences. Journal of Youth Development, 11(3), 175-187. https://doi.org/10.5195/JYD.2016.470

Shefter, L., Uhrman, A., Tobin, L., \& Kress, J. (2017). Inclusion coordinators at Jewish summer camps: Roles and challenges. Journal of Jewish Education, 83(1), 69-84.

Walker, A. N., Barry, T. D., \& Bader, S. H. (2010). Therapist and parent ratings of changes in adaptive social skills following a summer treatment camp for children with autism spectrum disorders: A preliminary study. Child \& Youth Care Forum, 39(5), 305-322. https://doi.org/10.1007/s10566-010-9110-x

White, E., Zippel, J., \& Kumar, S. (2020). The effect of equine-assisted therapies on behavioural, psychological and physical symptoms for children with attention deficit/hyperactivity disorder: A systematic review. Complementary Therapies in Clinical Practice, 39, 101101. https://doi.org/10.1016/j.ctcp.2020.101101

Wilson, C., Sibthorp, J., \& Brusseau, T. A. (2017). Increasing physical activity and enjoyment through goal-setting at summer camp. Journal of Park and Recreation Administration, 35(4), 24-36. https://doi.org/10.18666/JPRA-2017-V35-I4-7930

Woods, S., \& Cronin, A. (2018). Camp Gizmo: A unique venue for interprofessional collaboration. The American Occupational Therapy Association, 3(1), 2-4.

Zwicker, J. G., Rehal, H., Sodhi, S., Karkling, M., Paul, A., Hilliard, M., \& Jarus, T. (2015). Effectiveness of a summer camp intervention for children with developmental coordination disorder. Physical \& Occupational Therapy In Pediatrics, 35(2), 163-177. 


\section{Appendix A}

Online Staff Survey

\section{Camp Inclusion Survey}

The purpose of this survey is to gather feedback on inclusion within camp programming as it relates to occupational therapy. I'm looking to identify the needs of Pathfinder Ranch and strategies to promote inclusion. Your answers, along with other data, will be used to complete a needs assessment and create an in service.

Please remember that your participation in the survey is voluntary and anonymous. There are no right or wrong answers. Please take your time and respond honestly, your participation is extremely appreciated.

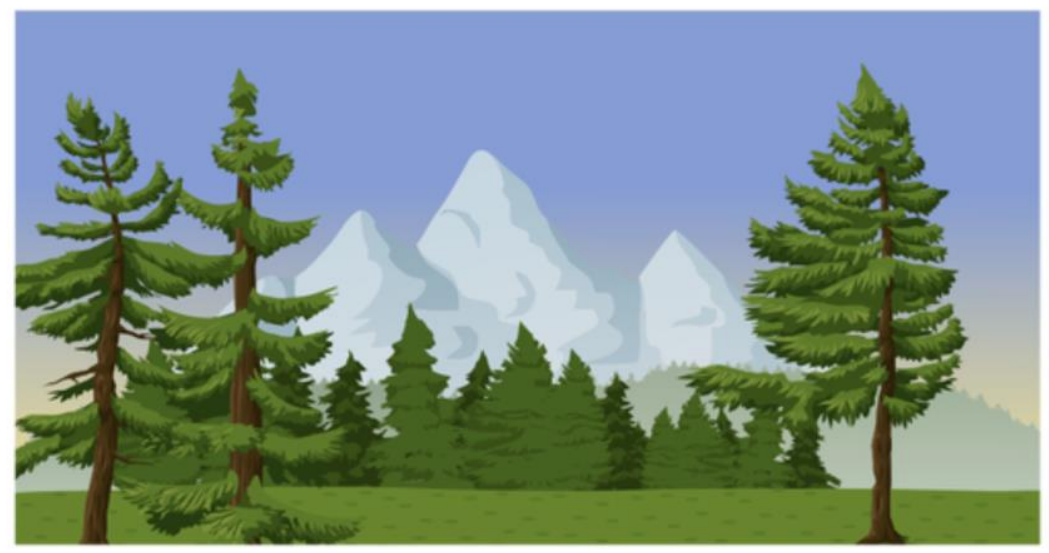

Your answer

1. What does inclusion mean to you? 
2. I feel confident working with kids with different needs?

Strongly disagree

Disagree

Neither agree nor disagree

Agree

Strongly agree

Other:

3. I have the tools, education, and resources to promote inclusion?

Strongly disagree

Disagree

Neither agree nor disagree

$\bigcirc$ Agree

Strongly agree

Other:

4. What strengths and supports do you see at Pathfinder Ranch? For example a support may be inclusion awareness training or open discussions. 
5. What barriers or limitations can you identify at Pathfinder Ranch which may hinder inclusion?

Your answer

6. What activities do you find to be the most challenging when including all participants?

Your answer

7. Have you ever worked at a segregated camp for youth with disabilities?

Yes

No

8. How many children with different abilities have you worked with in a camp setting?

0-3 children

4-6 children

7-12 children

13-20 children

21-29 children

$30+$ children

Other:

9. What strategies have you used to overcome challenges with inclusion? For example, if a child was unable to participate in a specific camp activity. 
10. What is your approach to ensure all kids are included?

Your answer

11. Do you have suggestions to promote inclusion within the activities at Pathfinder Ranch?

Your answer

Thank you for taking the time to fill out this survey. If you have any questions or suggestions please feel free to leave them below.

Your answer 


\section{Appendix B}

\section{Camp Inclusion Trivia Game}

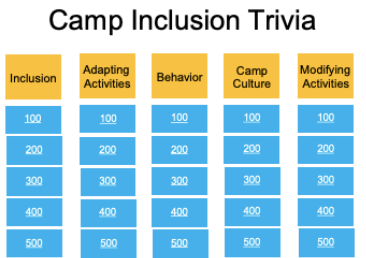

$\$ 200$ Answer Column 1

True, youth with different or special needs are at a higher risk of social isolation and often have challenges forming peer bonds.

\section{\$400 Question Column 1}

What are a few ways you could promote inclusion within your lesson plan?

\section{$\$ 500$ Answer Column 1}

Only $2 \%$ of ACA camps exclusively youth with special needs.

\$200 Question Column 2

How could you adapt a night hike to accommodate a group with different needs?

\section{$\$ 300$ Answer Column 2}

To promote comprehension of verbal directions or instructions, you could say the answer and have the group repeat it back.

OE: "We're going to build a fort. What are we going to build?" Students: "A fort!!!"

\section{$\$ 100$ Answer Column 1}

Inclusion means everyone being able to participate in the community in ways that recognize strengths and provide opportunities for challenge.

$\$ 300$ Question Column 1

What percent of ACA camps are inclusive?

A. $7 \%$

B. $10 \%$

C. $25 \%$

D. $40 \%$

\section{\$400 Answer Column 1}

To promote inclusion within a lesson plan, you could: use inclusive language, offer choices, give breaks, partners, ask a coworker for advice, or provide visuals.

\section{$\$ 100$ Question Column 2}

In your own words, explain modify versus adapt.

\section{\$200 Answer Column 2}

To adapt a night hike, you could take a shorter route, use

flashlights for challenging

terrain, hike to the outdoor theater, and share star stories.

\section{\$400 Question Column 2}

On a night hike, how could you adapt one of the games?

\section{\$200 Question Column 1}

T/F Youth with different or special needs are at risk of experiencing social isolation and social challenges.

$\$ 300$ Answer Column 1

A, only $7 \%$ of ACA camps are inclusive.

\section{$\$ 500$ Question Column 1}

What percent of ACA camps exclusively serve youth with special or medical needs?

\section{\$100 Answer Column 2}

Modify is to make a partial change where adapt is to make suitable to fit.

For example, to modify a writing prompt, you may ask a student to draw a picture, whereas you may give the entire group additional time to adapt to their needs.

\section{\$300 Question Column 2}

How could you adapt verbal directions or instructions to promote attention and comprehension?

\section{\$400 Answer Column 2}

To adapt a night hike game, you could have the kids clap instead of talk. 


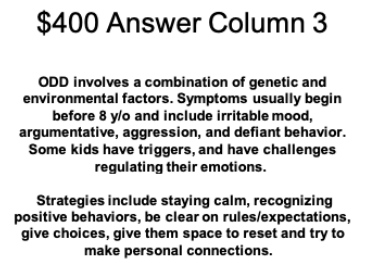

$\$ 100$ Question Column 4

T/F Camp enriches lives by providing positive experiences that have long-term effects.

\section{$\$ 200$ Answer Column 4}

True! "Science camp is about these kids learning to get dressed, put on their own damn socks, shower, and take care of themselves. This is the first time many have been away from home and their parents are here to do everything for them. Look these kids, no $\mathrm{Pads} / \mathrm{phones,}$ and they are truly enjoying being outside, building a shelter!

$\$ 400$ Question Column 4

What skills are semi-structured camp activities designed to promote? skills, and building group trust. adventure, they learn to adapt to the diversity of temperament and personality of ACA, author of Multiculturalism in Camps and Youth Programs

\$200 Question Column 5

How could you modify horseback riding?

\section{$\$ 500$ Question Column 3 \\ Name a poor behavior choice and how you handled the situation. \\ $\$ 100$ Answer Column 4 \\ True, each year, summer camps serve more than 11 million youth. Camp promotes positive youth development and growth.}

\section{$\$ 300$ Question Column 4} How does camp positively
impact youth?

\section{$\$ 400$ Answer Column 4}

Semi-structured camp activities are designed to promote creative thinking, teamwork, problem-solving

\section{\$100 Question Column 5}

Describe how you could modify an activity?

\section{\$500 Answer Column 3}

Many factors lead to poor behavior choices- home sick, out of comfort zone, tired, hungry, or challenging tasks.

\$200 Question Column 4

T/F Camp has the ability to improve independent living skills and increase outdoor affinity.

\section{$\$ 300$ Answer Column 4}

Camp can positively impact youth through positive experiences where everyone is included. Research shows individuals carry these positive experiences from childhood to adulthood.

\section{$\$ 500$ Question Column 4}

T/F Camp has the ability to teach youth cooperation, diversity, and respect.

\section{$\$ 100$ Answer Column 5}

To modify an activity, you could make a partial change.

For example shorten the activity, change the environment, add visual supports, or give additional rest breaks.

\$200 Answer Column 5

\section{$\$ 300$ Question Column 5}

To modify horseback riding, you could reassure student and walk side by side during

How could you modify the energy lesson plan? the ride. 


\section{$\$ 300$ Answer Column 5}

\begin{abstract}
To modify the energy lesson plan, you could partner student with chaperone or ask them to be your assistant.
\end{abstract}

$\$ 500$ Question Column 5

What are some ways you could modify a hike?
\$400 Question Column 5

How could you modify canoeing?
$\$ 400$ Answer Column 5

To modify canoeing, you could partner with a chaperone or strong group leader, limit the number of paddles, and reassure the participants.
$\$ 500$ Answer Column 5

Modifying a hike can be tricky. You could alter the route for a more stable path with a compact surface, shorten the hike, take additional rest breaks, or identify more plants/tracks/scat. 


\title{
Appendix C
}

\author{
Lesson Plan with Inclusion Tips
}

\section{Cultural History}

The San Jacinto Mountains, where Pathfinder Ranch is located, have a unique history that involves the Cahuilla Band of Indians, cattle ranchers, and miners. In this class, students get a chance to learn about and investigate these people, their history, and the artifacts they left behind.

\section{Cultural History Topics:}

Archaeology- Students will practice constructing explanations and making arguments from evidence while exploring how archaeologists learn about people who have lived here. Potential student activities include: Simulation dig site, observe artifacts Activities/Concepts Required: Simulation dig site or explore real artifacts/features/ecofacts Suggested: Smokehouse, archaeology site, bedrock mortars, using evidence to make inferences, limits of archaeology, material culture, and other aspects of culture.

Inclusion Tips: Encourage students to use other senses (e.g., hearing, touch, smell) to accommodate sensory differences. Ask the student to be your assistant to demonstrate inclusivity and teamwork.

Archery- Students will practice self-management and responsible decision-making while learning to safely shoot arrows. Students will also discuss how Cahuilla people use locally available materials for traditional hunting tools (including bows and arrows).

Activities/Concepts Required: Archery safety, shooting practice, materials used by Cahuilla people to make bows and arrows.

Suggested: Goal-setting, archery history, other hunting tools (ex/ throwing sticks), animals hunted

Inclusion Tips: To accommodate students who have challenges waiting for their turn, give them a job, such as helping to search for missing arrows. Allow the student to walk with chaperone. Provide a visual demonstration on how to line up the arrow. Let the chaperone hold the bow while the student releases the arrow. Use current adaptive archery equipment.

Ethnobotany- Students will develop a deeper understanding of the relationships people have with plants by reflecting on their own interactions with plants and learning to identify local plants that are culturally important to the Cahuilla.

Potential student activities include: Card hike of traditional plant uses, cordage making Activities/Concepts Required: Card hike, one hands-on activity (ex/ cordage, tea, or soap) Suggested: Definition of ethnobotany, overlook trail, cordage making, pinyon pine tea, yucca soap, traditional plant uses, plant observation (ex/ nature journaling, iNaturalist), introduce objects from the ethnobotany bin (uses and materials). 
Inclusion Tips: Hike a stable path with a compact surface. Give additional breaks to accommodate mobility concerns or low endurance. Allow students to illustrate (rather than write) journal responses to support cognitive processing. Pair student with chaperone and visual plant identification card to support social skills. Encourage students to use other senses (e.g., hearing, touch, smell) to accommodate sensory differences.

Fire- Students will explore a variety of perspectives about fire (including their own) while investigating the role of fire in local ecosystems.

Potential student activities include: Fire structures, friction fire Activities/Concepts Required: Perspectives on fire, ecological role of fire

Suggested: Flammability testing of local plants, local plant and animal adaptations to fire, reflection about students' own perspectives and emotions about fire, successful and problematic fire management strategies, fire risk, cultural burning, friction fire, fire safety, fire structures.

Inclusion Tips: Provide additional visual supports/drawings to accommodate different learning styles. Encourage students to use other senses (e.g., smell, hearing) to accommodate sensory differences. Ask the student to be your assistant to demonstrate inclusivity and teamwork.

\section{Earth's Resources}

Students will study the interconnectedness of earth's four spheres (geosphere, hydrosphere, biosphere, and atmosphere) by exploring earth's natural resources and their conservation.

Energy- Students will use the engineering design process to accomplish a variety of tasks and determine which energy source is the best fit for their purpose and use what they discover to reflect on responsible energy use.

Potential student activities include: Roasting marshmallows in the solar oven and solar robots Activities/Concepts Required: Energy conservation, hands-on activities

Suggested: Solar oven, scribble bots, LED circuits, fans, DIY windmill, energy ball, kinetic vs. potential energy, renewable vs. non-renewable energy sources, identify energy sources at camp.

Inclusion Tips: For challenges with processing verbal directions, create small groups. Present one step at a time. Check for completion and then present the next step. Ask the student to be your assistant to demonstrate inclusivity and teamwork. Provide additional visual supports/drawings to accommodate different learning styles.

Ethnobotany- Students will develop a deeper understanding of plants as a resource humans depend on by reflecting on their own interactions with plants and learning about uses of local plants by the Cahuilla. Potential student activities include: Card hike of traditional plant uses, cordage making Activities/Concepts Required: Card hike 
Suggested: Definition of ethnobotany, overlook trail, cordage making, pinyon pine tea, yucca soap, traditional plant uses, plant observation (ex. nature journaling, iNaturalist), introduce objects from the ethnobotany bin (uses and materials)

Inclusion Tips: Hike a stable path with a compact surface. Give additional breaks to accommodate mobility concerns or low endurance. Allow students to illustrate (rather than write) journal responses to support cognitive processing. Pair student with chaperone and visual plant ID card to support social skills. Encourage students to use other senses (e.g., hearing, touch, smell) to accommodate sensory differences.

Freshwater- Students will examine the role of water in the ecosystem while collecting, analyzing, and interpreting data on the quality of a local water source.

Potential student activities include: Macroinvertebrate hunt and $\mathrm{pH}$ testing Activities/Concepts Required: Water quality investigation, water conservation Suggested: Water as an essential resource, hydrologic cycle, aquifers, water sources for where our students come from, water usage by humans, (individual, manufacturing, agriculture, etc.), nonpoint source pollution, water as a limiting factor

Inclusion Tips: Provide a water sample at the table to accommodate mobility challenges. Encourage students to use other senses (e.g., hearing, touch, smell) to accommodate sensory differences. Ask the student to be your assistant to demonstrate inclusivity and teamwork.

Garden- Students will gain "hands in the soil" experience with gardening and understand the ways energy and matter transform as plants grow.

Potential student activities include: compost exploration and planting seeds

Activities/Concepts Required: Plant seeds to take home

Suggested: Compost exploration, energy cycles, photosynthesis, garden work, sample produce, human reliance on plants, agriculture and food systems

Inclusion Tips: Encourage students to use other senses (e.g., hearing, touch, smell) to accommodate sensory differences. Ask the student to be your assistant to demonstrate inclusivity and teamwork.

Geology- Students will explore stability and change by investigating how geological processes have shaped the land at Pathfinder Ranch.

Potential student activities include: Make a mineral key and erosion model

Activities/Concepts Required: Mineral Hunt

Suggested: Mineral key, rocks v. minerals, rock cycle, plate boundaries, erosion, where does sand come from, sand as a resource, mineral resources, earthquakes, build a mountain/erosion model.

Inclusion Tips: Bring a sample to the table to accommodate mobility challenges. Encourage students to use other senses (e.g., hearing, touch) to accommodate sensory differences and use additional visual supports. Ask the student to be your assistant to demonstrate inclusivity and teamwork. 


\section{Ecology}

Ecology is the scientific study of the relationships that living organisms have with each other and their natural environment. Students will explore the variety of ecological interconnections in our local pine chaparral environment.

Animals- Students will learn about the interdependence between animals and their environment by interacting with live animals in our Nature Center and observing firsthand how each animals' adaptations reflect structure and function.

Activities/Concepts Required: Nature Center Interactions

Suggested: Zookeeper, native/invasive species, how each animal is adapted to its 'home' ecosystem, animal care/feeding, O Deer (resource needs and population), compare/contrast adaptations, patterns/similarity/diversity

Inclusion Tips: Create small groups paired with chaperone to promote lower voice levels. Allow students to illustrate (rather than write) journal responses to support processing. Encourage students to use other senses (e.g., hearing, touch, smell) to accommodate sensory differences.

Fire- Students will consider the role of fire in ecosystems (especially our local chaparral-pine forest) by gathering information about the flammability and adaptations of local plants. Activities/Concepts Required: Flammability tests of local plants Suggested: Plant and animal adaptations to fire, fire game, characteristics of chaparral-pine forest, fire management strategies, positives and negatives of fires

Inclusion Tips: Provide additional visual supports/drawings to accommodate different learning styles. Encourage students to use other senses (e.g., smell, hearing) to accommodate sensory differences. Ask the student to be your assistant to demonstrate inclusivity and teamwork.

Forest- Students will examine systems within a forest by observing how biotic and abiotic parts of the forest interact.

Possible student activities include: Decomposing log investigation and food web Activities/Concepts Required: Photosynthesis

Suggested: Decomposing log (decomposition), characteristics of a forest, compare/contrast forest to meadow and/or chaparral, bark beetle investigation, food web, photosynthesis, cellular respiration

Inclusion Tips: Allow students to illustrate (rather than write) journal responses to support processing. Encourage students to use other senses (e.g., hearing, touch, smell) to accommodate sensory differences. Ask the student to be your assistant to demonstrate inclusivity and teamwork.

Freshwater- Students will examine the role of water in the ecosystem while collecting, analyzing, and interpreting data on the quality of a local water source.

Potential student activities include: Macroinvertebrate hunt and $\mathrm{pH}$ testing Activities/Concepts Required: Water quality investigation, water conservation 
Suggested: Water as an essential resource, hydrologic cycle, aquifers, water sources for where our students come from, water usage by humans, (individual, manufacturing, agriculture, etc.), nonpoint source pollution, water as a limiting factor

Inclusion Tips: Provide a water sample at the table to accommodate mobility challenges. Encourage students to use other senses (e.g., hearing, touch, smell) to accommodate sensory differences. Ask the student to be your assistant to demonstrate inclusivity and teamwork.

\section{Permaculture}

Permaculture focuses on sustainable connections between human society and natural environments, an emphasis on mimicking natural processes in every societal aspect, from farming practices to construction materials. This class, in particular, will utilize hands-on experiences with our animal and/or garden while studying animal husbandry, sustainability practices, energy cycles, and/or agricultural systems. Citizen science research might be incorporated into this class, depending on the teacher.

Farm- Students will discuss interdependence between humans and domestic animals while interacting with our farm animals.

Possible student activities include: Materials that include animal products and feeding the farm Activities/Concepts Required: Animal care, animal products humans use

Suggested: Wild v. domestic, adaptations, relationships between humans and domestic animals (ex/ livestock, pet, etc.), animal enrichment (pig forking, taking a goat for a walk), looking for eggs, wool dryer balls

Inclusion Tips: Encourage students to use other senses (e.g., hearing, touch, smell) to accommodate sensory differences. Ask the student to be your assistant to demonstrate inclusivity and teamwork.

Garden- Students will gain "hands in the soil" experience with gardening and understand the ways energy and matter transform as plants grow.

Potential student activities include: Compost exploration and planting seeds

Activities/Concepts Required: Plant seeds to take home

Suggested: Compost exploration, energy cycles, photosynthesis, garden work, sample produce, human reliance on plants, agriculture and food systems

Inclusion Tips: Encourage students to use other senses (e.g., hearing, touch, smell) to accommodate sensory differences. Ask the student to be your assistant to demonstrate inclusivity and teamwork.

Horseback-Riding- This concept will include an introduction to riding safety and equipment (e.g., helmet, saddle), and a trail ride (weather permitting). Since the horse ride takes half the period, this activity is paired with another activity like farm ( $1 / 2$ period) or horsemanship. Inclusion Tips: Provide an anxious student with additional reassurance and calming support. Pair with a seasoned horse. Walk side-by-side during the ride for safety. 
Horsemanship- This activity will include background information about horses and groundbased interactions with our horses while doing general husbandry tasks (e.g., grooming, feeding, picking hooves). This class can only be selected as a half period paired with farm or horse rides.

Inclusion Tips: Ask the student to be your assistant to demonstrate inclusivity and teamwork.

\section{Wilderness Skills}

The wilderness skills topic encourages an understanding of the harsh outdoor environment and essential equipment for outdoor activities. Overall, this topic helps students become better aware of their surroundings and learn about some important skills/equipment to safely participate in many outdoor activities.

Ethnobotany- Students will develop a deeper understanding of plants as a resource humans depend on by reflecting on their own interactions with plants and learning about uses of local plants by the Cahuilla.

Potential student activities include: Card hike of traditional plant uses, cordage making Activities/Concepts Required: Card hike

Suggested: Definition of ethnobotany, overlook trail, cordage making, pinyon pine tea, yucca soap, traditional plant uses, plant observation (ex/ nature journaling, iNaturalist), introduce objects from the ethnobotany bin (uses and materials)

Inclusion Tips: Hike a stable path with a compact surface. Give additional breaks to accommodate mobility concerns or low endurance. Allow students to illustrate (rather than write) journal responses to support cognitive processing. Pair student with chaperone and visual plant ID card to support social skills. Encourage students to use other senses (e.g., hearing, touch, smell) to accommodate sensory differences.

Fire- Students will learn about fire as a wilderness skill by building fire structures and evaluating when it makes sense to have a fire. Students will also discuss fire safety.

Potential student activities include: Friction fire and fire structures

Activities/Concepts Required: Fire structure building, fire safety

Suggested: Friction fire, flammability test, fire triangle, positives and negatives of wildfires, how fire affects survival scenarios

Inclusion Tips: Provide additional visual supports/drawings to accommodate different learning styles. Encourage students to use other senses (e.g., smell, hearing) to accommodate sensory differences. Ask the student to be your assistant to demonstrate inclusivity and teamwork.

Orienteering- Students will learn skills needed to find their way with a map and compass by navigating an orienteering course.

Potential student activities include: orienteering course and compass relay Activities/Concepts Required: Compass reading and compass course Suggested: Map reading, build a mountain (topo pieces), compass course in forest, build your own course, pacing, compass I Spy 
Inclusion Tips: Pair student with peer or chaperone to support social skills. Differentiate between 2D and 3D by drawing mountain range on knuckles (3D) and then opening your hand (2D). For challenges with processing verbal directions, create small groups. Present one step at a time. Check for completion and then present the next step. For pacing, demonstrate slowly, and then have students link elbows to pace together.

Survival Skills- Students will learn about the importance of responsible decision-making and preparation in having safe and fun outdoor adventures while working together to solve survival-themed scenarios.

Activities/Concepts Required: Preparation for outdoor activities and hands-on activity Suggested: Shelter-building, engineering design process, ten essentials, STOP (sit, think, observe, plan), Rule of Threes

Inclusion Tips: Pair with chaperone or peer to support social skills and team building. Ask the student to be your assistant when reviewing the shelters built.

\section{Wildlife}

Being adjacent to the San Bernardino National Forest and plenty of open space, Pathfinder Ranch is lucky to have a variety of local animals from gray squirrels to woodpeckers. The wildlife topic allows students an opportunity to conduct citizen science research while exploring our local environment for signs of animals, studying the differences between wild and domestic animals, plus observing their physical and behavioral adaptations.

Animals- Students will learn about the interdependence between animals and their environment by interacting with live animals in our Nature Center and observing firsthand how their adaptations reflect structure and function.

Activities/Concepts Required: Nature Center Interactions

Suggested: Zookeeper, native/invasive species, how each animal is adapted to its 'home' ecosystem, animal care/feeding, 0 Deer (resource needs and population), compare/contrast adaptations

Inclusion Tips: Create small groups paired with chaperone to promote lower voice levels. Allow students to illustrate (rather than write) journal responses to support processing. Encourage students to use other senses (e.g., hearing, touch, smell) to accommodate sensory differences.

Birds \& Nature Observation- Students will explore the natural landscape observing birds and their adaptations using tools like binoculars, guidebooks, and checklists.

Possible student activities include: Bird observation walk and how to use binoculars Activities/Concepts Required: Bird observation walk and birding checklist (send a checklist home with each student and adult)

Suggested: Owl pellets (only if it is necessary to move indoors), how to use binoculars, certainty vs. uncertainty in identification, bird adaptations of beak/feet/wing shape, bird habitats, unusual bird adaptations (bird true/false activity) 
Inclusion Tips: Allow students to illustrate (rather than write) journal responses to support cognitive processing. Encourage students to use other senses (e.g., hearing, touch, smell) to accommodate sensory differences. Ask student to be your assistant to demonstrate inclusivity and teamwork.

Farm- Students will discuss adaptations of domestic animals while interacting with our farm animals.

Possible student activities include: Farm animal interactions and wild vs. domestic Activities/Concepts Required: Animal care, animal products humans use

Suggested: Wild v. domestic, adaptations, relationships between humans and domestic animals (ex/ livestock, pet, etc.), animal enrichment (pig forking, taking a goat for a walk), looking for eggs, wool dryer balls, journaling

Inclusion Tips: Encourage students to use other senses (e.g., hearing, touch, smell) to accommodate sensory differences. Ask the student to be your assistant to demonstrate inclusivity and teamwork.

Herpetology- By observing herpetofauna (reptiles and amphibians) either in the wild or in our Nature Center, students will explore the adaptations, similarities, and differences between these two animal groups. Possible student activities include: Lizard hunt and nature center Activities/Concepts Required: Lizard hunt and/or nature center (temperature dependent) Suggested: Reptiles v. amphibians, identification of local lizards, lizard game, surface temperature investigation, reptile and amphibian adaptations, iNaturalist, vernal pool exploration (possible tadpoles in the spring)

Inclusion Tips: Create small groups paired with chaperone to promote lower voice levels. Allow students to illustrate (rather than write) journal responses to support cognitive processing. Encourage students to use other senses (e.g., hearing, touch, smell) to accommodate sensory differences.

\section{Ascent}

Ascent will challenge students individually while bringing them together to build a cohesive community. This class employs both kinesthetic and cognitive challenges to engage students in communication, cooperation, and problem-solving. During this topic, students will learn about working through challenges and how they can apply that perseverance back at home and school.

Climbing- Students will practice self-awareness, trying one of our climbing structures (climbing wall or alpine tower) or climbing real rocks in the National Forest (rock climbing). Before climbing, students will be introduced to safety protocol, equipment, and climbing commands. Inclusion Tips: Encourage student to take breaks during climb and, if necessary, to use current adaptive equipment. Allow student to walk with chaperone while waiting for their turn. 
Team Challenge- students will build teamwork and relationship skills like effective communication, resolving conflicts, and cooperating with others while completing fun challenges working together with their entire study group.

Inclusion Tips: Create a smaller group paired with chaperone or allow chaperone to support the group to promote success with a complex task. Encourage students to use other senses (e.g., hearing, touch) to accommodate sensory differences. 


\section{Appendix D}

\section{Recommendations for Pathfinder Ranch}

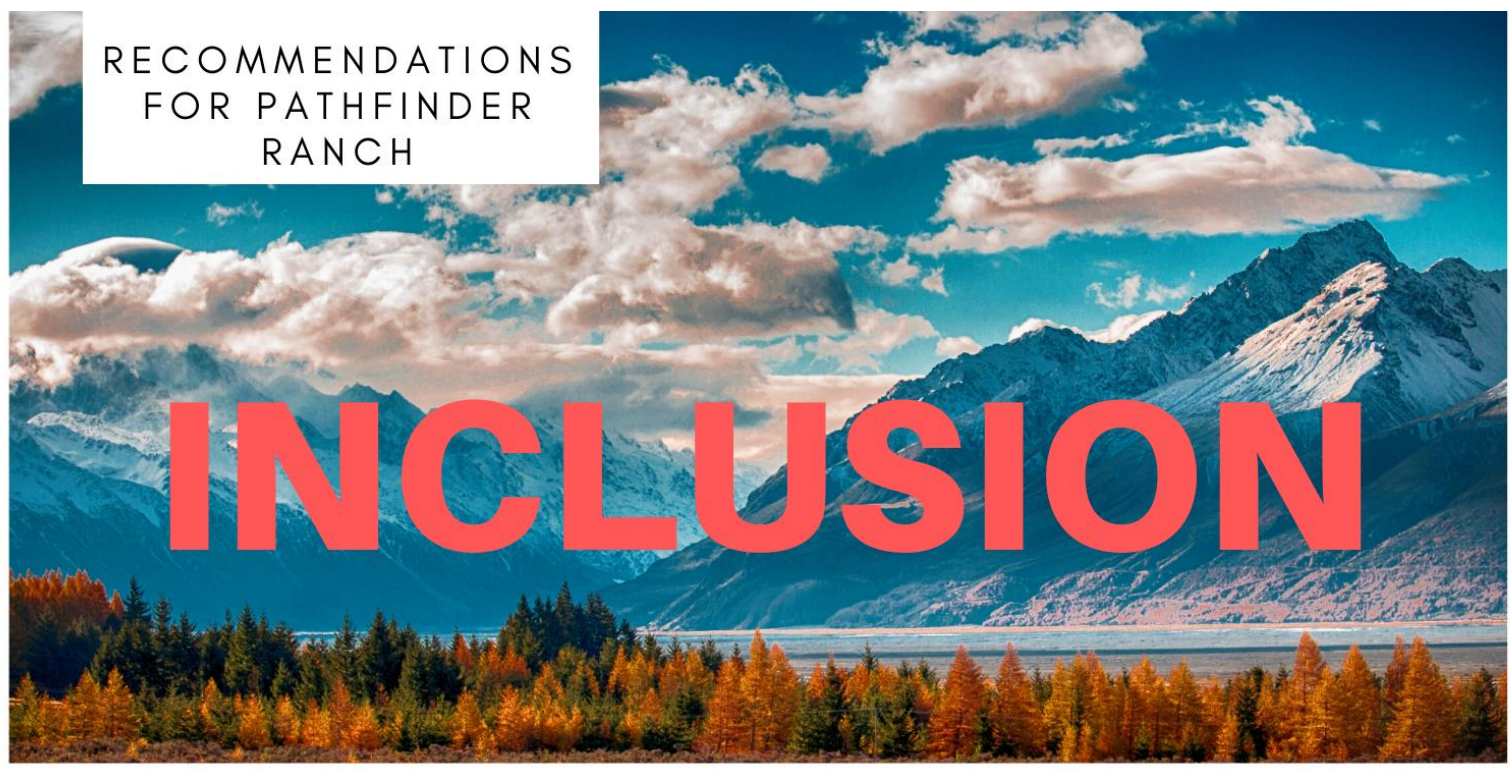

\section{HOW TO STRENGTHEN INCLUSIVITY}

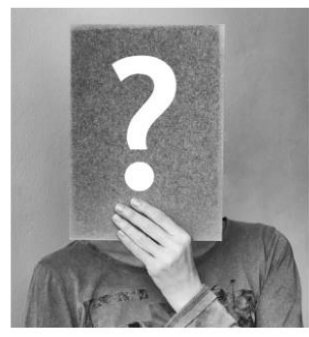

Additional Information on Camper

1. Examine participant intake form to identify areas for improvement in providing additional information to best support students

2. Following Family Educational Rights and Privacy Act (FERPA) guidelines provide information to OE staff which may support their lesson planning

3. Allow staff to collaborate with teacher/chaperone to gain a better understanding of the student's needs

4. Promote success and the just-rightchallenge

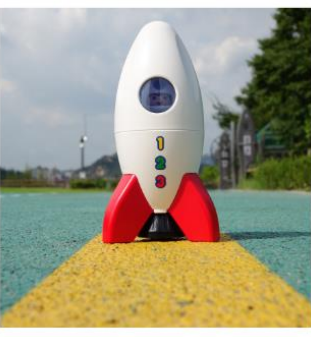

\section{Boost Inclusion Techniques}

1. Introduce staff to inclusion lesson plan as a resource for staff to save time with lesson planning

2. Increase conversations on inclusion techniques

3. Paint bow outline in archery area to promote successful completion of the activity

University OF ST. Augustine

- 1 FOR HEALTH SCIENCES

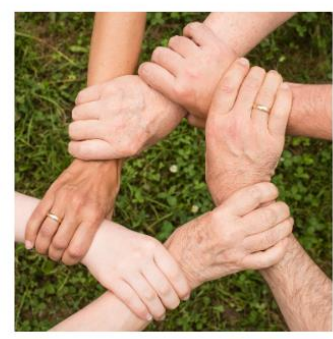

\section{Enhance Inclusion Training}

1. Online inclusion training through www.kit.org 2. Enhance foundational skills for working with diverse populations

3. Incorporate trivia game to increase knowledge and spark new ideas

4. Pair experienced staff with rookie staff for in-services on inclusion topics to encourage collaboration, coaching, and boost confidence 